\title{
A novel serotype of enteropathogenic Escherichia coli (EPEC) as a major pathogen in an outbreak of infantile diarrhoea
}

\author{
R. S. BARLOW, R. G. HIRST, R. E. NORTON*, C. ASHHURST-SMITH* and K. A. BETTELHEIM† \\ Department of Microbiology and Immunology, James Cook University, *Department of Microbiology, \\ Townsville General Hospital, Townsville and +National Escherichia coli Reference Laboratory, Victorian \\ Infectious Diseases Reference Laboratory, Melbourne, Australia
}

\begin{abstract}
An outbreak of infantile diarrhoea was investigated in 32 children, all $<2$ years old, in the tropical north of Australia. Rotavirus (63\%) and enteropathogenic Escherichia coli (EPEC) (59\%) were the most common pathogens identified. Of the 19 EPEC isolates, 14 (74\%) were of serotype O126:H12, hitherto unreported as an EPEC serotype. Other pathogens isolated included Salmonella spp. (16\%), Campylobacter spp. (3\%), Giardia (3\%) and Shigella spp. (3\%). EPEC-related gastro-enteritis is an uncommon but recognised cause of diarrhoeal outbreaks in Australia and clinicians need to be aware of the possibility of this serotype being implicated. This report highlights the disadvantages of relying on serotyping alone for the recognition of EPEC.
\end{abstract}

\section{Introduction}

Since enteropathogenic Escherichia coli (EPEC) strains were first recognised as pathogens $>50$ years ago, their involvement as a major cause of infantile diarrhoeal outbreaks throughout the world has been well documented [1]. EPEC-associated diarrhoeal outbreaks in developed nations were common in the past but EPEC do not appear to be important in these countries now. There have been few reports of EPEC-associated diarrhoeal disease in Australia over the last 20 years [2].

Traditionally, EPEC have been shown to belong to a number of distinct serogroups and were once defined solely on the basis of their serotype [1]. However, with increasing understanding of EPEC, the possession of specific $\mathrm{O}$ and $\mathrm{H}$ antigens is no longer considered an essential characteristic [3]. The Second International Symposium on EPEC in 1995 determined that a 'typical EPEC' should have the ability to produce the

Received 2 March 1999; revised version accepted 31 May 1999.

Corresponding author: Mr R. S. Barlow (e-mail: robert. barlow@foodscience.afisc.csiro.au).

Present address: Food Science Australia, Cnr Wynnum and Creek Roads, Cannon Hill, Queensland, Australia. attaching/effacing (A/E) lesion, lack Shiga toxin and possess the EPEC adherence factor (EAF) plasmid [4].

This report describes a diarrhoeal outbreak in an isolated Australian Aboriginal community that was associated with a high prevalence of EPEC of a novel serotype.

\section{Materials and methods}

Study area and population

A total of 32 children $<2$ years old was affected; all resided in a small isolated Aboriginal community near Townsville, North Queensland, Australia. Climatic conditions in this region are generally hot and humid with mean temperatures of $33^{\circ} \mathrm{C}$ in January and $19^{\circ} \mathrm{C}$ in August. The wet season usually occurs from late November to the end of March.

\section{Sample collection and preparation}

Faecal samples collected at the local health facility in the community were sent to the Queensland Health Pathology Services Laboratory at Townsville General Hospital for preliminary microbiological testing. Samples were cultured for Shigella, Salmonella, Aeromonas, Yersinia and Campylobacter spp. by standard microbiological methods. Samples were also screened for rotavirus (Vidas, bioMérieux, France). 


\section{Bacteria}

E. coli control strains included two EAF-positive strains (E990, C771) and one EAF-negative strain (E611), obtained from the National Escherichia coli Reference Laboratory, Victorian Infectious Diseases Reference Laboratory, Melbourne, Australia.

Five lactose-fermenting colonies of non-mucoid appearance were selected from each MacConkey Agar plate (Becton-Dickinson, Microbiology Systems, Cockeysville, USA) and subcultured on to Nutrient Agar (MicroDiagnostics, Queensland, Australia). The resultant colonies were screened by slide agglutination with OK polyvalent antiserum (Murex Diagnostics, Dartford). All isolates that agglutinated with the polyvalent antiserum were then serotyped in tests with all standard $\mathrm{O}$ antisera from $\mathrm{O} 1$ to $\mathrm{O} 173$ and all standard $\mathrm{H}$ antisera from $\mathrm{H} 1$ to $\mathrm{H} 56$ [5].

\section{PCR}

Isolates were examined for the presence of the EPEC adherence factor (EAF) plasmid [6], the bundleforming pilus (BFP) gene [7] and Shiga toxins 1 and 2 [8] by PCR as described previously.

\section{HeLa cell adherence assay}

HeLa cell adherence patterns were assessed by the method described by Scaletsky et al. [9].

\section{Results}

One or more of the recognised aetiological agents of diarrhoea were found in $30(94 \%)$ patients. Multiple infection with $E$. coli and rotavirus occurred in $50 \%$ of the patients. Rotavirus was the most frequently identified pathogen, accounting for $63 \%$ of the cases, followed by EPEC (59\%), Salmonella spp. (16\%), Campylobacter spp. (3\%), Giardia (3\%) and Shigella spp. (3\%). Only $12 \%$ of the patients had rotavirus as the sole pathogen. As the salmonellae isolated were of different serotypes, the cases were considered to be unrelated to each other.

Results of HeLa cell adhesion and PCR assays and serotyping (Table 1) showed excellent agreement between the genotypic and phenotypic assays. Of 21 $E$. coli isolates examined, 19 showed localised adherence (LA) in the 3-h assay and possessed the EAF plasmid and the BFP gene. All isolates were negative when tested for Shiga toxins 1 and 2. Of the six serotypes, O126:H12 was the most common (74\%) of the EPEC isolates. We believe this to be a novel EPEC serotype as it has not been reported previously.
Table 1. Characteristics of 21 isolates of $E$. coli identified in this study

\begin{tabular}{lcccc}
\hline $\begin{array}{l}\text { Serotype } \\
\text { Number of isolates }\end{array}$ & Adherence & \multicolumn{3}{c}{ PCR detection of } \\
\cline { 3 - 5 } if $>1)$ & pattern & EAF & BFP & Stx 1 and 2 \\
\hline O126:H12 (14) & LA & + & + & - \\
O55:H & LA & + & + & - \\
O69:H27 & LA & + & + & - \\
O99:H6 & LA & + & + & - \\
O119:H2 & LA & + & + & - \\
Ont:H10* & LA & + & + & - \\
O11:H55 & NA & - & - & - \\
O107:H27 & NA & - & - & - \\
\hline
\end{tabular}

LA, localised adherence; NA, no adherence pattern observed; EAF, EPEC adherence factor plasmid; BFP, bundle-forming pilus gene; Stx 1 and 2, Shiga toxins 1 and 2 .

${ }^{*} \mathrm{O}$ antigen not identified with $\mathrm{O}$ antisera $\mathrm{O} 1-173$

\section{Discussion}

EPEC infections exhibit seasonality and are associated with warm and wet weather [10]. This outbreak occurred in mid-winter, which is usually very dry in this region of tropical Australia. However, there was a longer than normal wet season which extended to the end of May. The wet season was accompanied by cyclonic conditions that gave rise to extensive flooding. Furthermore, there is little seasonal variation in temperature in this region, with average maximum temperatures in summer and winter differing by as little as $6^{\circ} \mathrm{C}$. These factors may explain the timing of this outbreak.

EPEC-associated diarrhoea is thought to be uncommon in developed countries and laboratories may no longer routinely screen for EPEC. Periodically, however, conditions may exist which mimic those in developing countries where outbreaks of EPEC are common. Thus, EPEC should not be discounted. Furthermore, this finding of a novel EPEC serotype (O126:H12) suggests that serotyping alone of $E$. coli isolates obtained from diarrhoeal outbreaks is useful but not definitive. This study highlights the need to use valid molecular methods for the detection of EPEC-associated virulence determinants.

\section{References}

1. Gomes TAT, Vieira MAM, Wachsmuth IK, Blake PA, Trabulsi LR. Serotype-specific prevalence of Escherichia coli strains with EPEC adherence factor genes in infants with and without diarrhea in São Paulo, Brazil. J Infect Dis 1989; 160: $131-135$.

2. Gunzburg ST, Chang BJ, Burke V, Gracey M. Virulence factors of enteric Escherichia coli in young Aboriginal children in north-west Australia. Epidemiol Infect 1992; 109: 283-289.

3. Edelman R, Levine MM. From the National Institute of Allergy and Infectious Diseases. Summary of a workshop on enteropathogenic Escherichia coli. J Infect Dis 1983; 147: 1108-1118.

4. Kaper JB. Defining EPEC. Rev Microbiol 1996; 27: 130-133.

5. Bettelheim KA, Thompson CJ. New method of serotyping Escherichia coli: implementation and verification. $J$ Clin 
Microbiol. 1987; 25: 781-786.

6. Franke J, Franke S, Schmidt $\mathrm{H}$ et al. Nucleotide sequence analysis of enteropathogenic Escherichia coli (EPEC) adherence factor probe and development of PCR for rapid detection of EPEC harboring virulence plasmids. J Clin Microbiol 1994; 32: $2460-2463$.

7. Gunzburg ST, Tornieporth NG, Riley LW. Identification of enteropathogenic Escherichia coli by PCR-based detection of the bundle-forming pilus gene. $J$ Clin Microbiol 1995; 33: $1375-1377$.
8. Brian MJ, Frosolono M, Murray BE et al. Polymerase chain reaction for diagnosis of enterohemorrhagic Escherichia coli infection and hemolytic-uremic syndrome. $J$ Clin Microbiol 1992; 30: 1801-1806.

9. Scaletsky IC, Silva MLM, Trabulsi LR. Distinctive patterns of adherence of enteropathogenic Escherichia coli to HeLa cells. Infect Immun 1984; 45: 534-536.

10. Levine MM, Edelman R. Enteropathogenic Escherichia coli of classic serotypes associated with infant diarrhea: epidemiology and pathogenesis. Epidemiol Rev 1984; 6: 31-51. 